\title{
Networked Operations Situation Awareness Share Based on Mental Model Sharing
}

\author{
Ying SHAO \\ Equipment Academy. \\ Beijing, China \\ E-mail: shao6116@163.com \\ Kang-Ming ZHANG \\ Equipment Academy. \\ Beijing, China \\ E-mail: kangmingzhang123@qq.com
}

\author{
Hao-Guang CHEN \\ Equipment Academy. \\ Beijing, China \\ E-mail: haoguangchen1212@163.com
}

\author{
Hao ZHANG \\ Equipment Academy. \\ Beijing, China \\ E-mail: 41198327@qq.com
}

\begin{abstract}
Sharing the networked operations situation awareness can guide the combat unit to have capability of joint combat via the joint operations. In order to build the share of situation awareness in the networked operation, this paper proposes a share method based on mental model sharing, shares the mental model of combat unit, receives the situation awareness and decision from the other units with the aid of network, predicts the motion that would be possibly taken in the future, and provides a new way to shape the autonomous joint among combat units.
\end{abstract}

Keywords-Networked operations; situation awareness sharing; Metal model sharing

\section{INTRODUCTION}

Networked operations to enhance the connectivity between the war units, so that personnel and equipment can be efficient and accurate and complete battlefield situation, the formation of the information advantage [1]. As the combat operations mainly depends on the awareness of the war staff rather than the objective battlefield situation, which makes the staff for the combat situation awareness has become a bridge between the battlefield situation and combat plan. With the increasingly complex combat operations and combat system structure, individuals are difficult to complete independent tasks. Networked operations Through the situation awareness sharing to enhance the commander's cognitive ability, with "power to the edge" concept, making the war unit can be formed through more flexible command and control to complete the specific purpose of the temporary combat team, Cooperate to achieve superior operational intent. The mental model is an important mechanism for the formation of awareness, which leads awareness of the formation of awareness elements, the formation of operational plans and action. Mental model sharing as an important way of Situation awareness has now been applied to multiple theories. When the combat units have a consistent mental model, and have a high degree of information security, awareness of the individual can form a consistent understanding of elements and decision-making, through independent cooperation to form a combat action to enhance the operational effectiveness of networked operations. In this paper, we propose networked operations Situation awareness method based on the sharing of mental models. The sharing of mental models can form cooperative operations and enhance the effectiveness of networked combat forces.

\section{SITUATION AWARENESS SHARING IN NETWORKED OPERATIONS}

In the 1990s, the concept of situation awareness was proposed by human factors, which described the individual's perception of information. The concept first emerged as a topic of interest within the military aviation domain [2], avia air traffic control domains [3] and other aspects. Ensley argues that situational awareness is the process by which individuals are making decisions and actions after forming posture perception and keeping and forming new situational awareness. Now she presents the three-level situation awareness model in a variety of areas has been the most widely used.

Through the network, sharing can make decent combat unit to form a combat system, in accordance with the superior intention to complete the combat mission. Battlefield network will be scattered throughout the deployment of combat elements to form a network of combat system. Through the situation awareness between combat units, to maximize the information advantage into decision-making advantages and operational advantages, enhance the effectiveness of the networked operations. Joint situational awareness, as a connection to the formation of operational capability of the system, plays a vital role in the play of networked operational effectiveness.

\section{SituATION AWARENESS SHARING BASED ON MENTAL MODEL SHARING}

The research areas of the mental model include ergonomics and cognitive psychology, its definition is still vaguer. Rouse and Morris [4], Johnson-Laird [5] made some definitions of the mental model concept. Bendy and Meister [6], Ensley illustrate the role of mental models in situational 
awareness. In situational awareness, the mental model is a structure of knowledge that expresses and predicts events, directs them to interact with others. The mental model connects the external environment elements with the decisionmaking and action of the perceived individual.

Mental model sharing is a mechanism of sharing, it is the formation of situational awareness of the important way to share, by activating instantaneous memory on the team and task-related knowledge, so that members involved in team action. Ensley believes that the use of shared mental models is more effective than oral communication to enhance situational awareness sharing [7]. Shared mental models Sharing among teams includes the ability to understand other members' roles, plans, information needs and potential replans in the team, as well as the ability to predict actions and feedback from other members. The shared mental model allows the team model to perform tasks with the same reference framework, making the interaction between teams more effective and making the actions of other team members predictable. When the communication means are limited, the shared mental model predicts the actions of other team members and Information needs [8].

\section{SHARING THE MENTAL MODEL IN NETWORKED OPERATIONS}

Mental model has input and output, Situation awareness individual according to their own cognitive level to understand input information and predict after the decisionmaking and action. In this paper, the mental model of situational awareness is understood as a decision model, the decision-making subject is to perceive the individual, the decision-making condition can be regarded as the battlefield situation information, and the decision result is the formed combat plan [9]. Decision making is the core of modern management science. In the early twentieth century, Taylor managed the scientific revolution to bring management into quantitative science. Modern management originated in the Second World War, and then the concept was likened to the non-military field. Decision-making in any field should aim to achieve more accurate and accurate decision-making information in the pursuit and realization of optimal system benefits, to develop a set of options that are viable, and to make decisions as much as possible through collective decision-making. The mental model forms operational decisions and actions by gathering battlefield situational awareness. The mental models of the members of the situational awareness sharing are strongly consistent, and they will form a consistent Situation awareness in the context of consistent operational intelligence. This makes it possible to make more accurate predictions of other members' operations, enabling them to cooperate with other unit operations. It can be seen that the synergies between the members of the combat and the formation of Situation awareness has a positive relationship. The networked combat system can be used as an important index to evaluate the team's ability to cooperate with each other. At the same time, according to OODA theory, the influence of delay on combat has become more and more obvious, the delay of combat decision-making process affects the whole combat time. Faster combat time makes the side of the battle ring can be embedded into the enemy combat ring, destroy the enemy combat process, paralyze its combat capability.

Networked operations ensure that Situation awareness has good connectivity between individuals so that they can communicate effectively and share information during operations. Information sharing is an effective means of forming situational awareness sharing, but communication and information sharing bring more pressure to perceive individual data processing ability, and information processing pressure prolongs the networked operational command process. Especially in high-intensity job assignments, the increase in working pressure makes it possible for individual to be unable to dispense with other information or complete communication. The dependence on the battlefield network has also brought fragility to the sharing, and it cannot be shared between individuals when the combat network fails.

The mental model sharing is different from the information sharing through the network, which can be shared when the Situation awareness individuals are independent. The prerequisite for the realization of Situation awareness sharing by mental model sharing involves the fact that the battlefield acquired by the individual at this time is true and at this time perceived that the individual has correctly obtained other mental models of members, in which case the individual is informed of the situation of the other members Situation awareness elements and decision making, action plans.

\section{VERIFICATION OF THE VALIDITY OF MENTAL MODEL SHARING IN NETWORKED OPERATIONS}

The mental model sharing in the networked operation completes the sharing of the situational awareness among the combat units, so that the combat units are informed of the situation of the other combat units and their plans and the next action. The Situation awareness individual mental model t can be shown in Fig. 1 below.

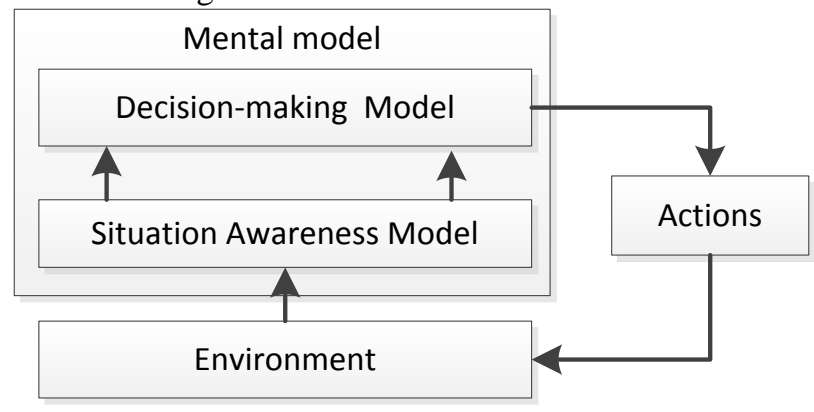

Figure 1 Relationship of action and environment to mental model

As mentioned above, when the combat real situation awareness individuals can obtain accurate battlefield information, the two Situation awareness individuals to obtain consistent battlefield intelligence information. When the mental model is consistent, the resulting Situation awareness product is also consistent. It can be argued that the Situation awareness individual can accurately obtain other individual Situation awareness products and decision-making, plan and so on through their own real battlefield information. Mental model sharing allows Situation awareness individuals to 
predict the actions of other members, and with their action plans to develop their own plans have played a better combat effectiveness. In order to verify that the other members' actions can improve the overall operational effectiveness, this paper sets out the situation and explains it through game theory. In this paper, the classical prisoner's dilemma model in game theory is used to illustrate the problem, which can be described by bivariate matrix.

\begin{tabular}{|c|c|c|c|}
\hline & & \multicolumn{2}{|c|}{ A } \\
\hline & & 1 & 2 \\
\hline \multirow{2}{*}{ B } & 1 & $-1,-1$ & $-9, \quad 0$ \\
\hline & 2 & $0,-9$ & $-6,-6$ \\
\hline
\end{tabular}

Figure 2. Prisoner's dilemma

According to the theory of game theory, when the individual perceived individual $\mathrm{A}$ does not know the other combat unit action, it will choose according to their own action 1, and in the two combat units are selected 2, A income is $-6, \mathrm{~B}$ income is -6 . A and $\mathrm{B}$ will choose action 1 when the situation awareness can be shared by the mental model to realize the action and action of the other party. At this time, the income of $\mathrm{A}$ is -1 and the income of $\mathrm{B}$ is -1 . A team consisting of $\mathrm{A}$ and $\mathrm{B}$ are considered optimal. The example proves that when the Situation awareness individual is informed of other members' action plans, the individual can form system performance through concerted action. It can be seen that the Situation awareness individuals have the ability to collaborate through the shared mental model and thus achieve better combat effectiveness.

The relationship between mental model sharing and networked operations performance improvement is shown in Fig. 2 below.

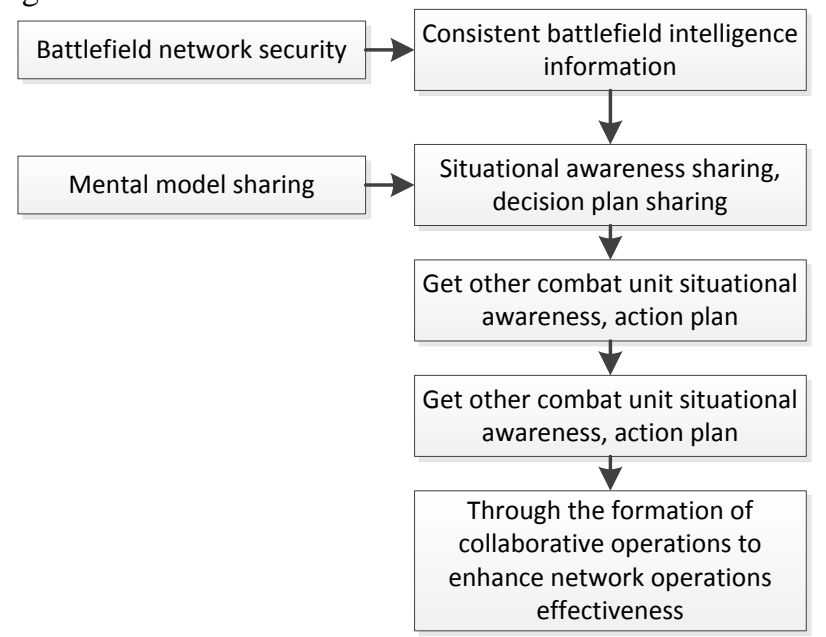

Figure 3. The Effect of Networked Operation and Sharing Mental Model on Operational Effectiveness

\section{CONCLUSION}

This paper presents a situational awareness sharing based on mental model sharing for networked operations. By sharing the mental model of the individual, the combat unit can obtain the situational awareness, decision and action plan of other combat units in time and accurately. Through the sharing of the mental model makes the individual through synergies to enhance the combat effectiveness of the troops. The research of this paper expands the new path for the study of situational awareness sharing in networked operations.

\section{ACKNOWLEDGMENT}

The authors sincerely thank HaoguangChen and HaoZhang for the discussion on situation awareness.

\section{REFERENCES}

[1] David ,S.A., John, J .Garstka., \&Richard, E. Hayes. Understanding Information Age Warfare [R]. Washington DC, USA: DoD Command and Control Research Program, 2001.

[2] Endsley, M.R. . Towards a theory of situation awareness in dynamic systems. Human Factors, 1995, 37:1, pp. 32-64..

[3] Endsley, M.R. . Asurvey of situation awareness requirements in air-toair combat fighters. The International Journal of Aviation Psychology, 1993.3:2, pp. 157-68.

[4] Rouse, W. B.,Morris, N. M. On looking into the black box: Prospects and limits in the search for mental models . Psychological Bulletin, 1986, 100: pp.349-363.

[5] Johnson-Laird P N. Mental models [M]. Cambridge. England: Cambridge University Press, 1983.

[6] Bedny , G. \& Meister, D. Theory of activity and situation awareness .International Journal of Cognitive Ergonomics, 1999, 3(1):pp.63-72.

[7] Endsley, M.R.,\& Kiris, E.O. Situation awareness Global Assessment Technique (SAGAT) TRACON Air Traffic Control Version User Guide. Lubbock TX: Texas Tech University,1995.

[8] Salas, E., Prince, C., Baker, P.D. and Shrestha, L. (1995). Situation awareness in team performance. Human Factors, 37, pp. 123-36.

[9] David R. Anderson, Dennis J Sweeney, Thomas A Williams. Quantitative Approaches to Decision Making (13 ${ }^{\text {th }}$ Edition). China Machine Press.BeiJing,2012. 